\title{
Saúde e Trabalho do Docente/Tutor no Ensino a Distância: uma análise da produção científica na perspectiva do desenvolvimento
}

\section{humano}

\author{
Health and Work Teacher/Tutor in Distance Learning: an analysis of scientific \\ literature on human development perspective
}

\author{
Flor de Liz Pereira Leão ${ }^{1}$ \\ Marluce Auxiliadora Borges Glaus Leão
}

Artigo recebido para publicação em Ago/2013 e aceito para publicação em Set/2013.

\begin{abstract}
RESUMO
Este artigo configura-se um levantamento bibliográfico que se propôs a conhecer a produção científica entre 2009 e 2013, cujo objeto fosse o trabalho do docente/tutor no contexto da Educação a Distância $(\mathrm{EaD})$, focalizando a questão do desenvolvimento humano e eventuais impactos dessa atividade laboral sobre a saúde desse profissional. Apresenta as produções encontradas em bases de dados virtuais - da Coordenação de Aperfeiçoamento de Pessoal de Nível Superior (CAPES) e da Biblioteca Virtual em Saúde (BVS). Discute os materiais encontrados no que se refere às suas diferentes abordagens, constatando que os materiais que tratam desse tema ainda são escassos. Não foram encontrados estudos abordando mais especificamente a questão do desenvolvimento humano ou dos impactos das atividades do docente/tutor de $\mathrm{EaD}$ à sua saúde. Conclui que essa pequena produção, que ocorria até o ano de 2006, ainda permanece conforme apurado também por outro estudo. Não obstante, vive-se em uma sociedade profundamente influenciada pelo conhecimento, pelas novas mídias, e a EaD é uma das modalidades da educação que mais crescem no País, requerendo um olhar mais crítico sobre seus desdobramentos na saúde dos profissionais que com ela trabalham.
\end{abstract}

Palavras-chave: Saúde do docente/tutor. Educação a distância. Desenvolvimento Humano.

\begin{abstract}
This article is a literature review seeking to investigate scientific, conducted between 2009 and 2013, they have had as object the work of the teacher / tutor of Distance Education (DE), focusing on the context of human development and the impacts that this labor activity has this health professional. Presents the research found in the databases of the Coordination of Improvement of Higher Education Personnel (CAPES). Presents the research found in the databases of the Coordination of Improvement of Higher Education Personnel (CAPES), since there were no occurrences in the search conducted in the Virtual Health Library (VHL). Quantifies and analyzes the research contained in the databases, with respect to the different approaches given to them as well as their results, noting that scientific production that deals with the subject is still very limited and has not been found any research that addresses the perspective of human development or specifically on the impacts of the activities of the teacher/tutor DE to your health. Concludes that the lack of studies on the subject remains as it was until the year 2006, as determined by Santos and Werchsler (2009), despite living in a society deeply influenced by knowledge and by new media and be the one DE modalities of education that grew most in the country.
\end{abstract}

Keywords: Health Teacher/Tutor. Distance Education. Human Development.

1 Mestranda em Desenvolvimento Humano: Formação, Políticas e Práticas Sociais. E-mail: flor.nead.mba@gmail.com

${ }^{2}$ Docente do Programa de Mestrado em Desenvolvimento Humano: Formação, Políticas e Práticas Sociais - PRPPG. E-mail: marluce@unitau.br 


\section{INTRODUÇÃO}

Constata-se que, desde meados do século XIX, a prática da Educação a Distância (EaD) era exercida por meio dos cursos de instruções, mediados pelos Correios, sendo a correspondência considerada um meio de comunicação muito importante e o primeiro modelo didático básico do Ensino a distância (SARAIVA 2006). Com a evolução no campo da tecnologia, da informação e da comunicação, observou-se sua consolidação como metodologia de ensino.

Essa evolução da EaD passou por várias fases, apresentando, segundo Moore (2007, p. 26), cinco gerações: correspondência; transmissão por rádio e televisão; universidades abertas; teleconferências e, por último, a geração da Internet/Web.

A disseminação da tecnologia e da Internet fez com que a Educação a Distância tivesse destaque no interior da sociedade contemporânea, proporcionando a organização de vários setores sociais, especialmente de Instituições de Ensino Superior, tendo em vista possibilitar um estudo autônomo e, por conseguinte, a autoaprendizagem. Claro que uma mudança desta envergadura não aconteceu de repente. Na realidade, segundo Castells (1999), o início desta mudança no meio social que permitiria chegar-se ao atual estágio de instrumentalização em que se encontra a Educação a Distância deve ser buscado por volta dos anos de 1970 do século passado. Lá se encontrariam as bases para aquilo que este teórico denomina sociedade informacional.

Por se tratar de um fenômeno ainda bastante recente, em termos históricos, muito há de incerteza e, até mesmo, de especulativo, na sua caracterização, ainda que alguns aspectos bem concretos já se delineiem para todos. Alguns dos aspectos mais importantes da sociedade informacional, ainda segundo Castells (1999), seriam: exigência de flexibilidade e adaptabilidade; convergência de diferentes tecnologias, notadamente as de informação; descentralização dos processos de produção; foco na produção de conhecimentos e necessidade contínua de atualização desses conhecimentos, numa constante interação, por meio de diversas formas e mecanismos de informação.

Desse modo, o que se depreende da construção teórica de Castells é que a sociedade em rede pressupõe uma profunda penetração e influência dessa nova 
configuração tecnológica em todas as instâncias da vida humana; que esse sistema tende para a construção de um novo modo de vida em que as instituições, tanto as da vida privada quanto as da pública, serão obrigadas a se organizar visando ter uma configuração mais flexível e mais ágil, para responder às demandas de uma sociedade cada vez mais veloz e fluida.

Cada vez mais, haverá convergências de mídias e de organizações, tentando responder às demandas de um mundo menos centralizado e mais globalizado. Nesse sentido, esse autor assim define o que chama de economia informacional e global:

\begin{abstract}
É informacional porque a produtividade e a competitividade de unidades e agentes nessa economia (sejam empresas, regiões ou nações) dependem basicamente de sua capacidade de gerar, processar e aplicar de forma eficiente a informação baseada em conhecimentos. É global porque as principais atividades produtivas, o consumo e a circulação, assim como seus componentes (capital, trabalho, matéria-prima, administração, informação, tecnologia e mercados) estão organizados em escala global, diretamente ou mediante uma rede de conexões e agentes econômicos. (CASTELLS, 1999, p. 87)
\end{abstract}

Afora esses aspectos, é significativo referir ainda que as empresas deslocaram seu foco do produto para o consumidor, diferentemente do que acontecia no auge da Revolução Industrial e, pouco a pouco, vai deixando de ter tanta importância a quantidade de horas trabalhadas e crescendo de valor a capacidade que tenha a empresa de dar plena satisfação aos anseios de consumo de seu público alvo (MASI, 2000). No entanto, isto não implica dizer que diminuiu a pressão sobre o trabalhador, uma vez que é um fato cada dia mais frequente a necessidade do cumprimento de metas de produtividade, que resultam em enorme estresse.

Dito isto, fica claro que, também no campo da educação, toda esta revolução tecnológica trouxe consequências. Uma delas é a possibilidade de maior acesso à educação, a qualquer pessoa, independentemente de tempo ou espaço (PETERS, 2001). Nesse contexto, a EaD, sem dúvida, foi uma das modalidades de ensino que mais se beneficiou com o surgimento das novas mídias.

No Brasil, a EaD se reporta a 1923, com a fundação da Rádio Sociedade do Rio de Janeiro, transmitindo programas de literatura, de línguas, de literatura infantil e de outros temas (RODRIGUES, 1998). Somente após a aprovação da Lei de Diretrizes e Bases da Educação (LDB), em 1996, ocorreu, com maior efetividade, o 
avanço e o desenvolvimento dos cursos na modalidade a distância.

Nesse sentido, a legislação educacional brasileira preceitua, no art. 80, da LDB, Lei no. 9.394/1996, regulamentada pelo Decreto № 5.622/2005, as seguintes características que lhe são pertinentes:

(...) modalidade educacional na qual a mediação didático-pedagógica nos processos de ensino e aprendizagem ocorre com a utilização de meios e tecnologias de informação e comunicação, com estudantes e professores desenvolvendo atividades educativas em lugares ou tempos diversos. (BRASIL, 2005, p. 2).

Segundo Neder (2005), a Educação a Distância exige do aluno grande envolvimento e compromisso com a produção do conhecimento. Portanto, é fundamental que o aluno tenha capacidade de articular o pilar "aprender a aprender", para que tenha um resultado positivo e possa se utilizar da EaD para tornar-se um cidadão de fato participativo e crítico dentro do contexto social.

Afinal, é primordial para um país que homens e mulheres sejam sujeitos formadores de idéias e possam enriquecer o processo informacional e cultural, que a cada dia se torna mais dinâmico, numa era em que o produto maior é o conhecimento. Para tanto, ainda segundo Neder, a Educação a Distância deve ser compreendida como:

Uma modalidade de educação que permite o compartilhamento, o diálogo entre os sujeitos, na busca da construção de significados sociais, possibilitando a constituição, por isso mesmo, de um espaço, não necessariamente físico, de interlocução entre os sujeitos da ação educativa (NEDER, 2005, p. 49).

E, de fato, a EaD configura-se atualmente como uma alternativa importantíssima na área educacional, capaz de ultrapassar as barreiras do tempo e do espaço. É uma modalidade de educação flexível, que dá oportunidade para que o estudante determine o seu horário de estudo, de acordo com as suas possibilidades e ritmo de aprendizagem.

Cabe enfatizar que a principal característica dessa modalidade de educação é a separação física entre o professor e os estudantes. Significa dizer que essa é uma forma diferente de estudar, ou seja, o estudante não conta com a presença direta do professor, ou seja, na prática, não existe relação face a face. A interação entre o professor e os estudantes é mediada pelos materiais impressos e pelos meios de comunicação disponíveis. Todavia, é inegável que a Educação a Distância amplia os espaços de aprendizagem e diversifica as formas de interação, 
principalmente agora, potencializados que foram os instrumentos midiáticos.

A gestão e o acompanhamento dos cursos realizados a distância são feitos geralmente por uma equipe multidisciplinar, responsável pelo bom andamento das atividades desenvolvidas. Assim, a Educação a Distância envolve os seguintes atores nessa modalidade de ensino: Diretor de Curso, Coordenador de Tutoria, Coordenador de Polo, Monitor, Docente/Tutor a Distância, Docente/Tutor Presencial.

Todavia, cabe destacar que, no contexto da sociedade em rede, também a escola que atua na modalidade a distância é uma organização, uma empresa, e seus atores, notadamente os profissionais que executam as diversas funções necessárias ao bom funcionamento dessa modalidade de ensino, são profissionais destas empresas, "operários do conhecimento", como o quer Drucker (2000), convivendo com os progressos inerentes a este novo momento histórico, e os problemas, incertezas e desafios que se impõem a todos. Neste artigo, entre os diversos profissionais que atuam no Ensino a Distância, o foco recai sobre o docente/tutor.

\section{DOCENTE TUTOR PRESENCIAL X DOCENTE TUTOR A DISTÂNCIA}

Segundo a Associação Nacional de Tutores na Educação a Distância Anated (2010), existem hoje, aproximadamente, 50.000 tutores em todo o país (SANTOS; FILHO, 2012 p. 1). De fato, constata-se um crescente aumento na demanda por essa função, especialmente junto às Instituições de Ensino Superior (IES) e, consequentemente, o surgimento de um perfil de trabalhador do magistério diferente do professor tradicional do ensino presencial.

$O$ profissional que trabalha no contexto da EaD desempenha funções semelhantes em relação ao professor tradicional, mas arca também com novas responsabilidades, como: atuar continuamente e de forma mais intensa com as novas mídias; estabelecer horários de atendimento a distância, junto às coordenações de $\mathrm{EaD}$; representar a instituição em situações de cunho administrativo que, em essência, deveriam caber à direção; manter regularidade do acesso ao ambiente virtual e dar retorno às solicitações dos estudantes em prazo pré-determinado, em alguns casos em, no máximo, 24 horas; responder aos alunos 
acerca de questões burocráticas da instituições que, igualmente, deveriam caber à direção, entre outras (MARANHÃO, 2009).

Schneider e Mallman (2011) apontam que o cargo ou função de "tutor" não consta como categoria profissional no contexto das relações trabalhistas, o que se soma aos vários elementos que desvalorizam o trabalho docente. Para esses autores, isso ocorre porque a função ainda não é regulamentada por lei, não obstante, na sua quase totalidade, os tutores terem formação no campo da docência.

A caracterização desta categoria de trabalhadores feita por Mill (2008, p.10) em relação à tutoria presencial aponta ser "composta pelo grupo de educadores que acompanha os alunos, presencialmente, com encontros frequentes ou esporádicos". Portanto, permite estar junto aos alunos, no mesmo lugar, ainda que fazendo uso das tecnologias midiáticas para orientar, acompanhar e incentivar a construção do conhecimento dos discentes. Na tutoria presencial, o atendimento pode ocorrer individualmente ou em grupo, em espaço próprio e estruturado para os encontros. Já a "tutoria virtual ou tutoria a distância" é dedicada ao acompanhamento dos educandos que se encontram em outro lugar, diferente daquele onde se encontra 0 tutor, por meio de tecnologias de informação e comunicação (MILL, 2008).

Conforme já visto, levando-se em conta as enormes transformações pelas quais passou o mundo, em todas as suas áreas, e as mudanças de paradigma que vêm acontecendo no âmbito do conhecimento, da educação e do trabalho, fica claro que esse profissional tende a se tornar, dia após dia, mais importante, bastando para isso observar o crescimento da modalidade a distância, conforme vem acontecendo no Brasil (INEP, 2011). Assim, percebe-se que aumenta a demanda por este tipo de profissional, e é importante pensar que tal quadro implica também uma nova configuração das relações de trabalho e de questões a serem equacionadas, entre elas a dos impactos à saúde de um profissional que, além de exercer atribuições comuns ao professor tradicional, tem de lidar com as ações específicas que envolvem a tutoria a distância. 


\section{SAÚDE LABORAL DO DOCENTE TUTOR EM EAD}

O trabalho ocupa um papel fundamental na inserção do indivíduo no mundo, contribuindo para a formação de sua identidade, permitindo-Ihe participar da vida social e é, inclusive, elemento importante para a saúde psíquica do ser humano. Porém, o histórico das conquistas por melhores condições de trabalho do homem é longo e cheio de percalços. Especialmente a partir do advento da Revolução Industrial, no século XVIII, constatam-se as desumanas condições de trabalho sob as quais vivia o operariado nesse período e que se estende até finais do século XIX, quando se inicia a reação da massa de trabalhadores, culminando nas primeiras leis de proteção (COTRIM, 2007).

Desse ponto em diante, depois do surgimento de instituições internacionais que tratam do tema, como é o caso da Organização Mundial do Trabalho (OIT), de fato muita coisa mudou, e as condições totalmente insalubres e desumanas com as quais conviveram os operários da primeira Revolução Industrial, embora ainda presentes em algumas regiões, já são tidas como inaceitáveis pela maioria esmagadora das sociedades. No Brasil, o movimento em direção à conquista de direitos pelos trabalhadores começa a se dar, mais efetivamente, na chamada Era Vargas, com a criação do Ministério do Trabalho e da Consolidação das Leis do Trabalho (CLT) (COTRIM, 2007).

Deste ponto em diante, no país, muitas conquistas foram alcançadas. A Constituição de 1988 estabeleceu o trabalho como um direito social do cidadão, prevendo a "redução dos riscos inerentes ao trabalho, por meio de normas de saúde, higiene e segurança" (BRASIL, 2008, p. 9), e o país tentou avançar no campo da legislação trabalhista. Visando dar conta desse preceito constitucional e pressionado pela sociedade civil, o Ministério da Saúde tem desenvolvido políticas de saúde e normas regulamentadoras para os trabalhadores. Nesse contexto, citamse várias delas, editadas ao longo dos últimos anos, com destaque para a NR ํㅡ 05 (que trata da prevenção de acidentes de trabalho), a NR no 06 (que trata da obrigatoriedade dos equipamentos de prevenção individuais - EPI) e a NR no 17 (que trata dos riscos ergonômicos) (BRASIL; 2007a; BRASIL, 2010; BRASIL, 2007b).

Quando se trata da profissão de professor, é ponto pacífico que esta é uma 
atividade que implica em grande desgaste, tanto físico quanto psicológico. Tanto que a própria Constituição, em seu artigo 40, § 5으, estabelece que o tempo de serviço dos professores que comprovem exclusivamente tempo de efetivo exercício de magistério na educação infantil, ensino fundamental e médio, deve ser reduzido em 5 anos, para efeitos de aposentadoria (BRASIL, 2008).

No entanto, o docente tutor do ensino a distância, por não ter suas atividades devidamente regulamentadas, ainda precisa buscar uma série de conquistas, inclusive as que o protejam dos riscos à sua saúde.

Segundo Mendes e Dias (1991, p. 347), a "saúde do trabalhador é definida como o processo saúde e doença dos grupos humanos, em sua relação com o trabalho". Não obstante ser esta uma definição bastante genérica permite pensar que a saúde envolve impactos de toda ordem, que vão do esforço físico até os psicológicos e relacionais e as singularidades do ambiente de trabalho.

Assim, em relação às condições de trabalho, especificamente na $\mathrm{EaD}$, Mill (2008) aponta como riscos trabalhistas deste ambiente o aumento da carga de trabalho dos docentes, as novas exigências impostas pelo uso das tecnologias digitais, o empobrecimento da mediação pedagógica por meio da atuação da tutoria e a precarização do trabalho, em termos de condições estruturais. Além desses riscos, Mill (2008) lembra outros, inclusive de cunho psicológico, tais como a sensação de angústia, a ansiedade e a solidão, além dos ergonômicos, como dores na coluna, mãos, pescoço, lombalgia, fibromialgia, hérnias, problemas oftalmológicos e posturais.

Considerando que as questões da saúde do docente tutor guardam estreita relação com o desenvolvimento humano, portanto, relevantes à investigação no que diz respeito às suas repercussões no âmbito do trabalho e da vida desses profissionais, procura-se definir a compreensão de desenvolvimento humano que aqui se assume.

\section{DESENVOLVIMENTO HUMANO}

O desenvolvimento humano, na perspectiva da Teoria Bioecológica, de Urie Bronfenbrenner, seu principal teórico, ressalta a importância e a influência dos 
ambientes no desenvolvimento dos indivíduos (PRATI et al., 2003). Nessa perspectiva, as pessoas apresentam características que mantêm certa configuração, dando o equilíbrio necessário ao indivíduo, constituindo sua personalidade, mas que podem sofrer modificações, sejam estas mais profundas com a passagem dos anos, ou circunstanciais, sobre o impacto do ambiente que o cerca (SAGAZ, 2008).

Portanto, o indivíduo, dependendo do ambiente, pode tornar-se mais motivado e capaz de se envolver em atividades que revelem suas potencialidades ou não. Além disso, ao revisar sua teoria, Bronfenbrenner ampliou a abordagem, passando a considerar a inter-relação de quatro núcleos conhecidos como PPCT (Pessoa, Processo, Contextos e Tempo).

O núcleo Pessoa destaca os fenômenos relacionados ao indivíduo em desenvolvimento, destacando as constâncias e as mudanças ao longo da vida do ser humano; o Processo se caracteriza pelos papéis e atividades diárias do ser humano, com destaque para os processos proximais; $O$ núcleo Contextos compreende a interação de quatro diferentes níveis ambientais (microssistema, mesossistema, exossistema e macrossistema); já o núcleo Tempo diz respeito às mudanças e continuidades que ocorrem ao longo da vida (SAGAZ, 2008).

Esses níveis, na perspectiva de Bronfenbrenner, formam o meio ecológico, que se constituiria de estruturas sistêmicas inseridas e articuladas entre si. No que diz respeito ao núcleo Contextos, o microssistema estaria relacionado às interações que $\mathrm{o}$ indivíduo estabelece face a face. $O$ mesossistema seria o conjunto de microssistemas de um indivíduo e a relação entre estes. O exossistema seria formado por ambientes não frequentados diariamente pelo indivíduo, porém que exercem influências sobre ele. $E$, finalmente, o macrossistema envolve a cultura e subculturas que permeiam a sua vida.

São esses núcleos e níveis que, na concepção teórica de Bronfenbrenner, formam o meio ambiente ecológico, constituindo-se, portanto, de estruturas sistêmicas inseridas e articuladas entre si. Porém, é importante destacar que na concepção do autor é preciso atentar para a pessoa e para o meio ambiente, mas "com especial atenção para a interação entre os dois" (BRONFENBRENNER, 1996 p. 14), posto que a pessoa não pode ser vista como um ser passivo, meramente à mercê das influências do ambiente, mas como um ser ativo, dinâmico, que sofre estas influências, mas que, igualmente, o interpenetra e, muitas vezes, o reestrutura. 
Logo, esta teoria deixa claro o peso dos ambientes sobre o desenvolvimento dos indivíduos, exercendo um papel significativo na sua formação e atuação, influenciando e sendo por eles influenciados.

Tendo em vista o contexto do trabalho e da saúde dos docentes tutores de EaD, definiu-se como objetivo deste levantamento bibliográfico conhecer os estudos disponíveis em dois bancos de dados científicos, acerca das questões que tratem da inter-relação desenvolvimento humano, trabalho e saúde, no ambiente em que atuam esses docentes.

\section{MÉTODO}

Trata-se de uma pesquisa de levantamento bibliográfico, realizada na base de dados virtual de teses e dissertações da Coordenação de Aperfeiçoamento de Pessoal de Nível Superior (Capes) e na base de dados da Biblioteca Virtual em Saúde - BVS, no mês junho de 2013. A pesquisa se circunscreve à produção científica que se refere ao tema deste trabalho, mais especificamente entre janeiro de 2009 e junho de 2013, sendo utilizado para a busca as expressões: saúde docente/tutor em EaD; saúde docente/tutor e trabalho; saúde docente/tutor e desenvolvimento humano.

A busca resultou em uma listagem com os títulos das produções (autor/ano). A leitura dos resumos possibilitou a identificação de materiais e a análise de conteúdo para (re) conhecer o assunto tratado em cada um dos artigos, atentandose principalmente para as variáveis investigadas e para os resultados obtidos.

\section{RESULTADOS E DISCUSSÃO}

No banco de dados da BVS, não foram encontradas produções correspondentes às expressões utilizadas. $\mathrm{Na}$ base de dados da Capes, foram encontradas 05 (cinco) produções, conforme especificados na tabela 1. 
Tabela 1. Distribuição da produção na base Capes, 2009-2013

\begin{tabular}{lccccc}
\hline Expressão & 2009 & 2010 & 2011 & 2012 & 2013 \\
\hline Saúde docente/tutor em EaD & 3 & 0 & 0 & 0 & 0 \\
Saúde docente/tutor e trabalho & 1 & 1 & 0 & 0 & 0 \\
Saúde docente/tutor e DH & 0 & 0 & 0 & 0 & 0 \\
\hline TOTAL & 4 & 1 & 0 & 0 & 0 \\
\hline
\end{tabular}

Fonte: Capes.

A partir desses dados, observa-se que os trabalhos encontrados com a expressão "Saúde docente/tutor em EaD", foram 03 (três), mas apenas 01 (um) tratava especificamente de tutoria a distância (SANTOS; WERCHSLER, 2009). No que diz respeito à "Saúde docente/tutor e trabalho", foram encontrados 02 (dois) trabalhos, mas que se referiam indiretamente aos aspectos que cercam o trabalho em EaD, o que demonstra uma preocupação ainda incipiente dos estudiosos. $\mathrm{Na}$ busca relacionada ao desenvolvimento humano, não foram encontradas pesquisas.

Em seguida, foram identificadas as áreas às quais as produções estavam associadas, encontrando-se os resultados listados na tabela 2.

Tabela 2. Distribuição da produção/área na base Capes, 2009-2013

\begin{tabular}{lccccc}
\hline Produções/Área & 2009 & 2010 & 2011 & 2012 & 2013 \\
\hline Saúde & 3 & 0 & 0 & 0 & 0 \\
Educação & 1 & 1 & 0 & 0 & 0 \\
\hline TOTAL & 4 & 1 & 0 & 0 & 0 \\
\hline
\end{tabular}

Fonte: Capes.

Além de observar-se que a produção científica é reduzida, as áreas que tratam dos temas se restringiram unicamente às de saúde e da educação, sendo duas do campo da Enfermagem e uma do campo da Medicina, o que mostra que a questão saúde do trabalhador ainda carece de atenção quando diz respeito ao tutor/docente em geral, e não apenas ao tutor a distância.

No que se refere à abordagem dos artigos da base de dados da Capes, foram encontrados os seguintes títulos: "Os anéis da serpente: a aprendizagem baseada em problemas e as sociedades de controle" (BATISTA; BATISTA, 2009); "Validação de jogo educativo para o ensino da valoração cardiovascular" (ARAÚJO et al., 2010); "A escola inclusiva e estratégias para fazer frente a ela: as adaptações curriculares" (HEREDERO, 2010); "Reflexões sobre o ensino de gestão em saúde no internato de Medicina na Faculdade de Ciências Médicas da UNICAMP" (CARVALHO, CAMPOS, OLIVEIRA 2009); "Ensino à distância: uma década das publicações científicas brasileiras" (SANTOS; WERCHSLER, 2009). 
O artigo de Batista e Batista (2009) é uma análise crítica acerca do método denominado Aprendizagem Baseada em Problemas (ABP), no contexto do curso de Medicina. Os autores utilizaram como principais referenciais teóricos as obras de Foucault e Deleuze e a obra literária de Franz Kafka. De Foucault, utilizam-se da teoria sobre o poder na vida da sociedade moderna, tratando dos aspectos anátomo-políticos (o corpo enquanto máquina a ser otimizada e disciplinada rumo à docilidade e à produtividade) e do corpo biopolítico (elementos biológicos e sociais, tais como reprodução, nascimento e morte) das populações. De Deleuze, enfatizam que saúde e educação, mesmo em pleno século XXI, podem ser concebidas, pedagogicamente, como um processo contínuo de controle, estabelecido na origem, no momento de formação dos profissionais que atuam nessas áreas. Para ilustrar essas questões lançam mão da obra de Kafka, notadamente o romance

Processo.

Batista e Batista (2009) concluem que, mesmo um método como a ABP, dependendo da forma como é utilizado, pode contribuir para que se mantenham as estruturas da sociedade de controle e da sociedade disciplinar, conforme definidas pelos teóricos utilizados pelos autores, mas que, ainda assim, o método pode servir como importante instrumento que quebre a compartimentalização de conteúdos tradicionais nos cursos de Medicina. No entanto, não chegam a abordar o tema EaD.

O segundo artigo, de Araújo et al. (2009), também se volta para a pedagogia utilizada no campo da saúde, agora nos cursos de Enfermagem. Os autores avaliaram o material educativo que se utilizou de jogos como recurso pedagógico, no ensino do conteúdo valoração cardiovascular. Nessa pesquisa, 30 (trinta) enfermeiros experientes avaliaram os alunos que foram ensinados através da utilização de jogos como recurso pedagógico. Concluem, a partir da avaliação dos enfermeiros, que a utilização de jogos apresentou consonância, interatividade, coerência e validez pedagógica no processo de aprendizagem, embora também não tenham se referido a aspectos de $\mathrm{EaD}$ ou da atuação dos docentes/tutores.

Carvalho, Campos e Oliveira (2009) e Heredero (2010) não se referem à $\mathrm{EaD}$ e aos docentes/tutores. Focam, novamente, em reflexões sobre o ensino de gestão em saúde, no âmbito da Medicina (CARVALHO; CAMPOS; OLIVEIRA, 2009) e acerca da escola inclusiva e das adaptações curriculares (HEREDERO, 2010), mais especificamente a importância do Documento de Adaptação Curricular 
Individual (DACl), para a melhoria do processo de inclusão dos alunos com deficiência, o que, ainda que não fosse o foco principal do autor, tem impactos no desenvolvimento humano destes alunos. Afinal, este é um instrumento introduzido no ambiente escolar que o reestrutura de forma a favorecer o desenvolvimento das pessoas com deficiência. Nesse sentido, se demonstra a perspectiva de Bronfenbrenner (1996), ou seja, que os indivíduos não são seres passivos, mas dinâmicos, capazes de reestruturar um ambiente.

Por último, Santos e Werchsler (2009) tratam, mais especificamente, das questões referentes à $\mathrm{EaD}$. Os autores analisaram os artigos que tiveram como tema a Educação a Distância num período bem anterior, ou seja, entre 1997 e 2006. Identificam de pronto uma série de problemas na redação de resumos dos artigos, de tal forma que somente 52 (cinquenta e dois) foram analisados por eles. Concluíram que ocorre um aumento da produção a partir de 2002, com um leve pico em 2006. No entanto, os autores citam que ainda é uma produção pequena e restrita a poucas áreas, principalmente à área das ciências da saúde. A população mais estudada nos artigos investigados por esses autores foi a de adultos. Os estudos voltados para o uso da Educação a Distância nos ambientes corporativos corresponderam apenas a $3,85 \%$ do total e, tanto nestes, quanto nos demais, não havia nenhum estudo especificamente voltado para os impactos à saúde dos docente tutores da EaD.

Dessa forma, Santos e Werchsler (2009) consideram que os estudos encontrados sobre a $\mathrm{EaD}$ na área da saúde são poucos e que é preocupante a participação quase imperceptível das áreas da Psicologia e da Educação na produção científica voltada para a EaD. Sugerem que talvez não esteja sendo dada a atenção devida a este tema no âmbito acadêmico, embora esta seja a modalidade de ensino que mais vem ganhando força nos últimos anos.

Constata-se nesse levantamento bibliográfico que, de 2006 até o presente momento, o quadro não apresentou mudanças, e a produção acadêmica focada em EaD, saúde dos docentes/tutores e desenvolvimento humano continua incipiente, faltando atenção dos estudiosos, notadamente dos campos da Educação, da Psicologia e da Administração. 


\section{CONSIDERAÇÕES FINAIS}

Neste levantamento bibliográfico, a escassez de pesquisas que tratam das questões referentes ao docente/tutor na $\mathrm{EaD}$, aos impactos que tenha esta modalidade de ensino à saúde deste profissionais e ao seu desenvolvimento humano, de que falam Santos e Werchsler (2009), se mantém. Tanto é que, dentre os 05 (cinco) estudos tratados, não foi encontrada nenhuma pesquisa abordando as questões relativas a desenvolvimento humano, e o único que toca diretamente nas questões da EaD ainda é o dos autores supracitados.

Além disto, com exceção do estudo de Santos e Werchsler (2009), não foi encontrada nenhuma pesquisa que tivesse como foco, especificamente, os impactos das atividades laborais dos docentes/tutores à sua saúde, no contexto das instituições de ensino. Quando considerada uma abordagem mais geral, esses autores detectaram a existência de apenas 3,85\% de pesquisas estudando o uso da Educação a Distância nos ambientes corporativos. Ora, como uma grande parte dos docentes/tutores atua em grandes empresas privadas da área da Educação, sequer este aspecto tem sido um significativo alvo de estudo.

Nesse sentido, lembra-se o alerta de Castells (2009), de que na atualidade deve-se levar em conta o fato de se viver em uma sociedade em rede, modo de vida este em que cresceram brutalmente de importância a influência das novas mídias e o papel do conhecimento nas mais diversas instâncias da vida humana.

Como visto, uma das áreas da Educação que mais cresceram devido a estas transformações foi exatamente a EaD, de tal forma que existem hoje aproximadamente cinquenta mil docentes/tutores atuando no país, conforme dados da Anated já referidos (SANTOS; FILHO, 2012). Logo, por ser um panorama bastante recente, denotando desafios e incertezas e, no tocante especificamente à atuação dos docentes/tutores, que não contam sequer com um marco jurídico seguro, voltado para suas atividades, entende-se que essa seja uma área de pesquisa profícua para a comunidade acadêmica investigar os diversos aspectos que envolvem a atuação desses profissionais, com ênfase, sobretudo, no desenvolvimento humano, cada vez mais importante neste contexto em que vive a Educação. 


\section{REFERÊNCIAS}

ARAUJO et al. Validação de jogo de educação para o ensino de avaliação cardiovascular. 2010. Disponível em:

<http://aprendeenlinea.udea.edu.co/revistas/index.php/iee/article/viewArticle/5483/72 68 > Acesso em: 10 fev. 2013.

BATISTA, Rodrigo. S.; BATISTA. Rômulo. S; Os anéis da serpente: a aprendizagem baseada em problemas e as sociedades de controle. 2009. Disponível em: <http://www.scielo.br/pdf/csc/v14n4/a19v14n4.pdf > Acesso em: 12 fev. 2013.

BIBLIOTECA VIRTUAL EM SAÚDE. Disponivel em: <http://www.bireme.br/php/index.php >. Acesso em: 26 jan. 2013.

BRASIL. Ministério do Trabalho e Emprego. Secretaria de Inspeção do Trabalho (SIT). Departamento de Segurança e Saúde no Trabalho (DSST). Norma Regulamentadora $\mathbf{N}^{\circ}$ 05: acidentes de trabalho. Brasília: MTE, SIT, DSST, 2007a.

. Ministério do Trabalho e Emprego. Secretaria de Inspeção do Trabalho (SIT). Departamento de Segurança e Saúde no Trabalho (DSST). Norma Regulamentadora $\mathbf{N}^{\circ}$ 17: ergonomia. Brasília: MTE, SIT, DSST, $2007 \mathrm{~b}$.

BRASIL. CLT e Constituição Federal. 35 ed. atual. aum. São Paulo: Saraiva, 2008.

. Ministério do Trabalho e Emprego. Secretaria de Inspeção do Trabalho (SIT). Departamento de Segurança e Saúde no Trabalho (DSST). Norma Regulamentadora $N^{\circ}$ 06: equipamento de proteção individual - EPI. Brasília: MTE, SIT, DSST, 2010.

. Ministério da Educação. Decreto № 5.622, de 19 de Dezembro de 2005. Regulamenta o art. 80 da Lei 9.394, de 29 de dezembro de 1996, que estabelece as diretrizes e bases da educação nacional. Disponível em:< http://www.planalto.gov.br/ ccivil_03/_Ato2004-2006/2005/decreto/D5622.htm >. Acessado em: 16 out. 2012.

BRONFENBRENNER, Urie. A ecologia do desenvolvimento humano: experimentos naturais e planejados. Porto Alegre: Artmed, 1996.

CARVALHO, Sérgio Resende; CAMPOS, Gastão Wagner de Sousa; OLIVEIRA, Gustavo Nunes de. Reflexões sobre o ensino de gestão em saúde no internato de medicina na Faculdade de Ciências Médicas da Universidade Estadual de Campinas: Unicamp. Interface, Botucatu, v.13, n.29, p. 455-465, 2009. Disponível em: <http://dx.doi.org/10.1590/S1414-32832009000200017>. Acesso em: 15 ago. 2012

CASTELLS, Manuel. A sociedade em rede. 6 ed. São Paulo: Paz e Terra, 1999.

COORDENAÇÃO DE APERFEIÇOAMENTO DE PESSOAL DE NÍVEL SUPERIOR. Disponível em: <http://www.capes.gov.br/index.php>. Acesso em: 26 de jan. de 2013. 
COTRIM, Gilberto. História global: Brasil e geral. 8. ed. São Paulo: Saraiva, 2007.

DRUCKER, Peter. O futuro já chegou. Exame, São Paulo, n. 710, p. 112-126, março, 2000.

HEREDERO; Sebastian. A escola inclusiva e estratégias para fazer frente a ela: as adaptações curriculares. Revista Serviço Social e Realidade, Maringá, v. 32, n. 2, p. 193-208, 2010.

INSTITUTO NACIONAL DE ESTUDOS E PESQUISAS EDUCACIONAIS - INEP. Disponível em:<http://www.inep.gov.br/> Acesso em: 10 de janeiro de 2013.

MARANHÃO. UNIVERSIDADE ESTADUAL DO MARANHÃO. Manual de tutoria. São Luís: UEMA, 2009.

MASI, Domenico de. O ócio criativo. Rio de Janeiro: Sextante, 2000.

MENDES, R.; DIAS, E.C. Da Medicina do Trabalho à Saúde do trabalhador. Rev. Saúde Púb. São Paulo, no 25 v.5, p. 341-349, 1991.

MILL, Daniel et al. 0 desafio de uma interação de qualidade na educação a distância: o tutor e sua importância nesse processo. São Carlos: 2008. Disponível em: http:// http://www.sead.ufscar.br/outros/artigo-mill. >. Acesso em 10 abr. 2012.

MOORE, Michel. G; KEARSLEY, Greg. Educação a distância: uma visão integrada. São Paulo: Thomson Learning, 2007.

NEDER, Lucia. A educação a distância e a formação de professores: Possibilidades de mudança paradigmática. In: PRETI, Oreste (Org.) Educação a distância: sobre discursos e práticas. Brasília: Liber Livro, 2005.

PRATI, Laissa. et al, S. Revisitando a inserção ecológica: uma proposta de sistematização. Porto Alegre: UFGRS, 2003. Disponível em: <www.scielo.br/prc> Acesso em: 10 fev. 2012.

PETERS, Otto. Didática do ensino a distância. São Leopoldo: Unisinos, 2001.

MALLMANN, E. M.; SCHNEIDER, D. R. Tutoria em Educação a Distância: indicadores para Políticas Públicas. In: CONGRESSO INTERNACIONAL ABED DE EDUCAÇÃO A DISTÂNCIA 17.,2011, Manaus. Anais... São Paulo: ABED, 2011.

RODRIGUES, Rosângela Schwarz. Modelo de avaliação para cursos no ensino a distância: estrutura, aplicação e avaliação. Dissertação (Mestrado em Engenharia de Produção) - Universidade Federal de Santa Catarina, Florianópolis, 1998.

Disponível em: <http://www.eps.ufsc.br/disserta98/roser/index.htm>. Acesso em: 10 ago. 2012.

SAGAZ, V. R. Crianças e adolescentes vítimas de abuso sexual e o processo de resiliência: 
perspectiva de compreensão a partir da abordagem ecológica do desenvolvimento humano de Bronfenbrenner. 2008.188p. Dissertação (Mestrado em Educação) Universidade Estadual de Ponta Grossa. Ponta Grossa, 2008.

SANTOS, Eliana; WERCHSLER, Solange Muglia. Ensino à distância: uma década das publicações científicas brasileiras. Interam. j. psychol. [online]. 2009, v.43, n.3, p. 558-565. ISSN 0034-9690. Disponível em: <http://pepsic.bvsalud.org/scielo.php>. Acesso em: 10 abr. 2012.

SANTOS Francilene D.; FILHO Claudimar.Q. M.; Desafio de uma nova profissão no cenário educacional. 2012. Disponível em:

$<\mathrm{http}: / /$ www.anated.org.br/index.php?option=com_content\&view=article\&id=372\&cati $\mathrm{d}=53$ \&ltemid=192> Acessado em: 10 fev. 2013.

SARAIVA, Terezinha. Educação a Distância no Brasil: lições da história. Em Aberto, Brasília, ano 16, n. 70, abr./jun. 2006, p. 17-27. 